from the urethra grew no pathogen. He made a full recovery when treated with benzyl penicillin 1 mega unit intramuscularly six hourly.

His wife, who was without symptoms at this time, eventually agreed to be examined. She had cervicitis without erosion but no clinical evidence of urthritis. Cultures, however, grew the gonococcus from both sites.

This family demonstrates once again the well-known latency of gonorrhoea in women, and it also seems very likely that the condition had remained latent in the husband until septicaemia ensued though no proof of this can be obtained The most unusual finding was the development of one of the rarest of the complications of gonorrhoeanamely, gonococcal septicaemia in both husband and wife. We have not been able to find a similar example recorded in the literature.-We are, etc.,

J. K. OAtes Westminster Hospital,

V. H. PATTERSON

Oates, J. K., British Medical fournal, 1971, 3,
580.

\section{How Infectious is Gonorrhoea?}

SIR,-Dr. A. S. Wigfield (16 December, p. 672) provides some evidence that gonorrhoea is a highly infectious disease and that there is litle difference in the infectivity rates for males and females. This is remarkable when one considers that gonococci implanted on the cervix are not exposed to the considerable fluid flows present in the male urethra during micturition. Further, the cases described by Dr. W. K. E. Bernfield (21 October, p. 173) show that within an hour after intercourse gonococci can be anchored to the urethral mucosa and are able to resist the flow of urine. In a recent electron-microscope study of human gonorrhoeal we have demonstrated the specific adherence of gonococci to cells from the urethral mucosa (see fig.). This attachment can explain the ability of the gonococcus to maintain itself in the urethra despite micturition.

Currently we are investigating the mechanism of this attachment. Freshly isolated London S.W.1

gonococci possess long hair-like filaments, pili, which can be seen radiating from the cells on electron microscopy. ${ }^{2}$ On subculture in the laboratory these gonococci mutate to lose their pili. Our preliminary results show that gonococci with pili have a much greater ability to attach to human fibroblasts than the non-pilated mutants of the same strain. Furthermore, a scanning electron-microscope study of human Fallopian tubes maintained in an organ bath during perfusion with pilated gonococci has revealed organisms apparently anchored down to the epithelial surface by their pili. It would seem likely, then, that the critical factor in the high infectivity of gonorrhoea is the ability of pilated gonococci to attach to mucosal cells. Nevertheless, the non-pathogenic neisseria which grow on mucosal surfaces are also pilated, ${ }^{3}$ suggesting that other factors, such as resistance to host defence systems," must be important in the virulence of the gonococcus.-We are, etc.,

Southampton General Hospital

M. E. WARD

St. Mary's Hospital,

P. J. WATT

London $W .2$

Ward, M. E., and Watt, P. J., Foumal of Infectious Diseases, 1972, 126, 601

2 Swanson, J., Kraus, S. J., and Gotschlich, E. C., Fournal of Experimental Medicine, 1971, 134, 886.

3 Wistreich, G. A., and Baker, R. F., Fournal of General Microbiology, 1971, 65, 167 .
Ward, M. E., Watt, P. J., and Glynn, A. A.,
Nature, 1970, 227, 382.

\section{Glove-powder Peritonitis}

SIR,-Following the publication of my letter on glove-powder peritonitis (17 July 1971 , p. 183) and a scientific paper by $\mathrm{Mr}$. Julian Neely and Mr. J. Douglas Davies (11 September 1971 , p. 625) considerable correspondence has been received indicating that this type of peritonitis is much more common than was supposed. It seems that there is no substitute for the corn starch used, and the only way of avoiding this complication is to avoid the corn starch. One of the principal glove manufacturers kindly produced for a trial period gloves prepared

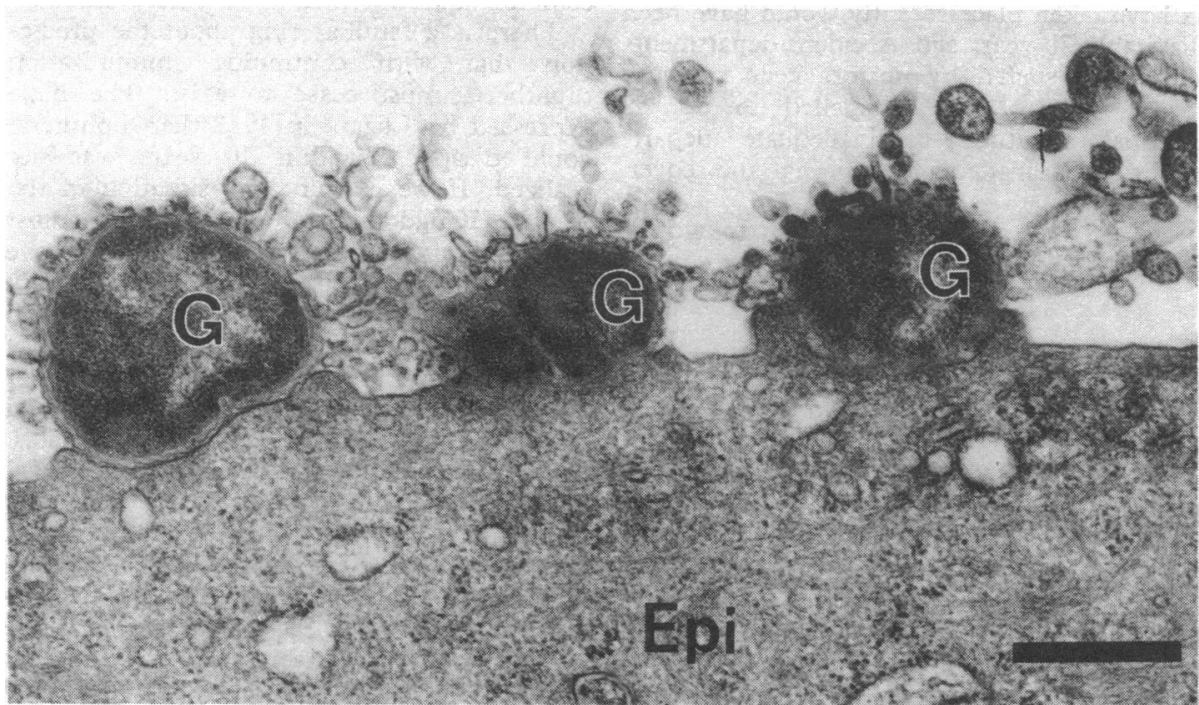

FIG. 1.-Electron micrograph showing gonococci (G) closely adherent to the surface of a urethral epithelial cell (Epi) from a male patient with early
symptomatic gonorrhoea. The bar represents $500 \mathrm{~nm}$ fectious Diseases 1 by permission of the University without the use of the corn-starch powder, which is normally applied as a slurry at the end of the manufacturing process. These gloves, gamma-ray sterilized, were a little more difficult to apply because it was necessary for the hands to be really dry. However, they not only eliminated completely the powder risk, but were a tremendous improvement in quality and did not become sticky in use; the grip was very much more satisfactory at the end of a long period of operating. These gloves were tried by various surgeons in different parts of the country and unfortunately the consensus of opinion was against their use on account of the difficulty of application. The manufacturers will therefore not proceed with this project as a commercial undertaking. For those who cannot dry their hands adequately, the difficulty of application could be overcome by the use of Bio-Sorb cream, a cornstarch preparation (which can be supplied in sachets). This avoids the use of scattered powder. It seems incredible that this risk to patients, acknowledged as very real, has got to continue because of the additional expense of manufacturing safe gloves.

There is little doubt that now we are aware of the risk of corn-starch peritonitis legal liability, in the event of this developing, must fall fairly and squarely on the surgeon and the manufacturers. Rubbing the gloves with a swab wetted with cetrimide removes much of the powder. but even after such a vigorous application and rinsing there is still a considerable amount remaining ingrained in the surface of the glove, as shown by a subsequent rinsing. A quick rinse alone is utterly insufficient. The only way of avoiding the risk is the elimination of powder in manufacture. Surely commercial considerations must be overcome.I am, etc.,

London S.E.19

\section{F. ELLISON NASH}

\section{Pulmonary Oedema in Pulmonary}

Thromboembolism

SIR,-One of the reasons for the poor diagnostic rate ${ }^{1}$ in the very common ${ }^{2}$ condition of pulmonary thromboembolism is the variety of ways in which it may be manifest. Your report (30 December, p. 773) of an excellent clinicopathological conference on heart failure in a middle-aged woman contains a statement by Dr. Celia Oakley that "pulmonary embolism . . does not cause pulmonary oedema." Since the appearance unchallenged of this statement in your columns suggests that this is a commonly accepted view, we wish to draw attention to the considerable contrary experimental and clinical evidence.

In $1942 \mathrm{Megibow}$ et al. ${ }^{3}$ demonstrated that pulmonary oedema frequently complicated experimental pulmonary embolization in dogs. Dexter in $1965^{4}$ observed that in patients with preexisting heart disease the only manifestation of pulmonary embolism may be a subtle worsening of cardiac function, often presenting itself as pulmonary congestion or occasionally as florid pulmonary oedema. During the past few years we have had the opportunity to study 11 patients who presented with pulmonary oedema that was shown after full investigation, including haemodynamic measurements of Chicago Press.) 